\title{
Fingerprinting of cell lines by directed amplification of minisatellite-region DNA (DAMD)
}

\section{L.M. Silva, \\ $\mathrm{H}$. Montes de $\mathrm{O} \mathrm{ca}$, \\ C.R. Diniz and \\ C.L. Fortes-Dias}

\author{
Centro de Pesquisa e Desenvolvimento, Fundação Ezequiel Dias (FUNED), \\ Belo Horizonte, MG, Brasil
}

\begin{abstract}
\section{Correspondence}

C.L. Fortes-Dias

Centro de Pesquisa e

Desenvolvimento, FUNED

Rua Conde Pereira Carneiro, 80

30510-010 Belo Horizonte, MG

Brasil

Fax: +55-31-3371-9432

E-mail: consuelo@funed.mg.gov.br

TThis paper is dedicated to

H. Montes de $\mathrm{O}$ ca, in memoriam.

Research supported by FAPEMIG L.M. Silva was the recipient of an undergraduate fellowship from FAPEMIG (TEC 995/96).

The development of in vitro propagation of cells has been an extraordinary technical advance for several biological studies. The correct identification of the cell line used, however, is crucial, as a mistaken identity or the presence of another contaminating cell may lead to invalid and/or erroneous conclusions. We report here the application of a DNA fingerprinting procedure (directed amplification of minisatellite-region DNA), developed by Heath et al. [Nucleic Acids Research (1993) 21: 5782-5785], to the characterization of cell lines. Genomic DNA of cells in culture was extracted and amplified by PCR in the presence of VNTR core sequences, and the amplicons were separated by agarose gel electrophoresis. After image capture with a digital camera, the banding profiles obtained were analyzed using a software (AnaGel) specially developed for the storage and analysis of electrophoretic fingerprints. The fingerprints are useful for construction of a data base for identification of cell lines by comparison to reference profiles as well as comparison of similar lines from different sources and periodic follow-up of cells in culture.
\end{abstract}

Received July 19, 2001

Accepted August 14, 2001

\section{Introduction}

The development of cell culture methods has been an extraordinary technical advance for several biological studies, with the great advantage of easy standardization. Nevertheless, the correct identification of the cell line used is crucial, as a mistaken identity or the presence of another contaminating cell may lead to invalid and/or erroneous conclusions. Eventual contamination by bacteria or fungi can be easily identified by micro- or even macroscopic examination of the cultures, due to the high speed at which these organisms grow in the culture media. To

\section{Key words}

- DNA fingerprinting

- DAMD

- Cell line

- Cell culture 
Distinct molecular methods, especially those based on DNA amplification by the polymerase chain reaction (PCR), have been introduced for the identification and characterization of organisms in general. In cases where there is no previous knowledge of the genome sequence under investigation, amplification techniques using arbitrary primers were developed $(7,8)$. One drawback of these randomly primed reactions, soon recorded, was the low stringency necessary for successful amplification, which could lead to non-reproducible results (9). One alternative proposed to increase reproducibility was the methodology named directed amplification of minisatellite-region DNA (DAMD), based on the amplification of minisatellite or variable number of tandem repeat (VNTR) sequences at relatively high stringencies (10).

We report here the application of DAMD to the characterization of cell lines available in our cell bank. Analysis and storage of the generated DNA fingerprints were greatly facilitated by data digitalization and further evaluation with a software (AnaGel) specially developed for this purpose.

\section{Material and Methods}

\section{Cell lines}

Twenty samples of 15 distinct cell lines (Table 1) from the cell bank in our laboratory were grown in appropriate culture media, which were prepared from individual components as described (11) and sterilized by filtration through 0.22 - and $0.1-\mu \mathrm{m}$ pore membranes.

\section{DNA extraction}

A minimum of $1.0 \times 10^{8}$ cells were used for extraction of genomic DNA, performed with the GenomicPrep Cells and Tissue DNA

Table 1. Cell lines used for DAMD fingerprinting.

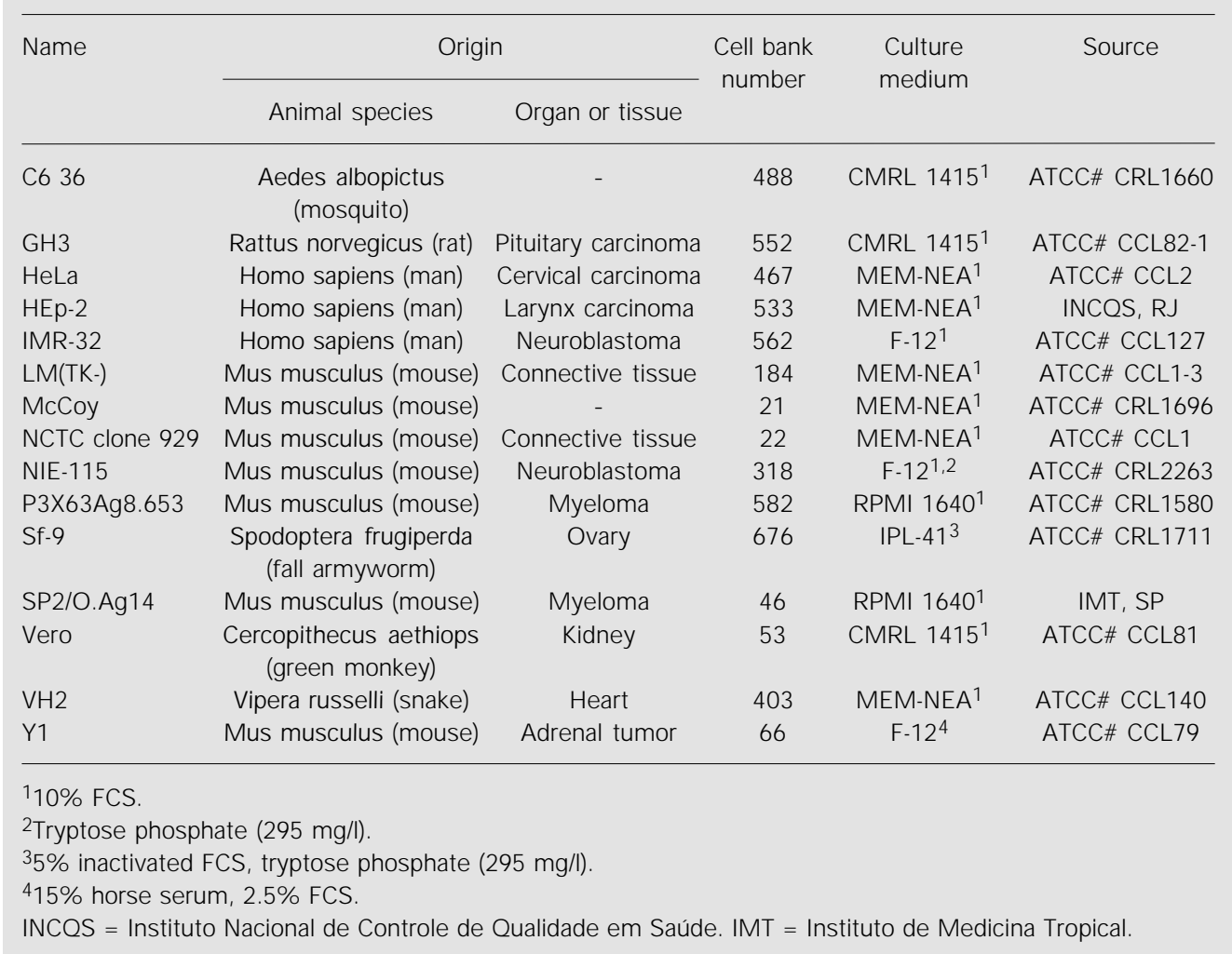


Isolation kit (Amersham Pharmacia Biotech, Uppsala, Sweden) according to manufacturer instructions. The DNA was eluted in $100 \mu \mathrm{l}$ of $1 \mathrm{X}$ TE buffer and its concentration estimated by absorbance readings at 260 and 280 nm (Gene-Quant, Amersham Pharmacia Biotech, Uppsala, Sweden).

\section{DNA amplification}

DNA was amplified in a thermocycler (Perkin-Elmer model 2400, Foster City, CA, USA) using PCR reagents acquired from Amersham. The reaction mixture was prepared as follows: $10 \mu \mathrm{l} \mathrm{PCR}$ buffer $(100 \mathrm{mM}$ Tris- $\mathrm{HCl}, 500 \mathrm{mM} \mathrm{KCl}, 15 \mathrm{mM} \mathrm{MgCl} 2, \mathrm{pH}$ 9.0), $4.2 \mu \mathrm{l}$ dNTPs (25 mM each), $0.75 \mu \mathrm{g}$ primer, $6 \mu \mathrm{l}$ (1.25 U) Taq DNA polymerase, $240 \mathrm{ng}$ DNA, and ultrapure water for a total reaction volume of $60 \mu \mathrm{l}$. After incubation for $5 \mathrm{~min}$ at $94^{\circ} \mathrm{C}$, amplification was performed for 35 cycles of $1 \mathrm{~min}$ at $94^{\circ} \mathrm{C}, 60 \mathrm{~s}$ at $55^{\circ} \mathrm{C}$ and $90 \mathrm{~s}$ at $72^{\circ} \mathrm{C}$. When necessary, $\mathrm{MgCl}_{2}$ concentration was varied within the 1.5 to $4.0 \mathrm{mM}$ range. The VNTR sequences used as primers were: INS (5' ACA GGGGTGTGGGG 3') and M13 (5' GAG GGTGGNGGNTCT 3') (10). A negative control (with no DNA) was run in all amplifications.

\section{Gel electrophoresis}

Twenty microliters of the amplification products was analyzed on $2 \%$ agarose gels (7 $\mathrm{x} 10 \mathrm{~cm}$ ) in $1 \mathrm{X}$ TBE buffer for $60 \mathrm{~min}$ at 100 $\mathrm{V}$, and stained with ethidium bromide. The amplified fragments were visualized under UV light. A 1-kb DNA ladder (Gibco BRL, Gaithersburg, MD, USA) was used as size marker.

\section{Images analysis}

Gel images were digitalized using an EDA Kodak 1D system and saved as bmp files for analysis by the AnaGel software specially

developed for storage and analysis of electrophoretic data (12). Besides managing a generic data bank of gels and samples with traditional tools for data bank searches, the AnaGel software is able to search for similarity between stored records. Briefly, the images are processed after delimitation of the work area onto the gel, established by top and bottom drawing lines. The lanes to be processed are chosen and a screen form is filled with sample characteristics and run conditions. The fragment bands are normalized per lane according to the DNA marker on the same gel. The software allows lane comparisons and alignments within the same or two different gels, and generates a characteristic fingerprint that can be stored in a data bank. AnaGel software is available free at <www.sirius.cenapad.ufmg.br/anagel/ anagel.html>.

\section{Results}

Initially, DNA amplification of cell lines was performed in the presence of $1.5 \mathrm{mM}$

A

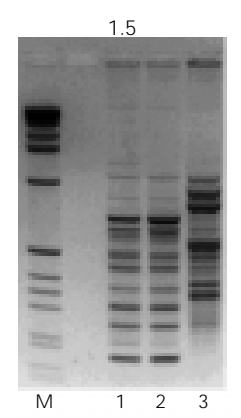

C

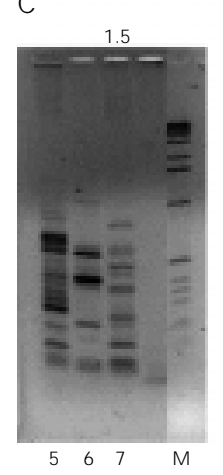

B

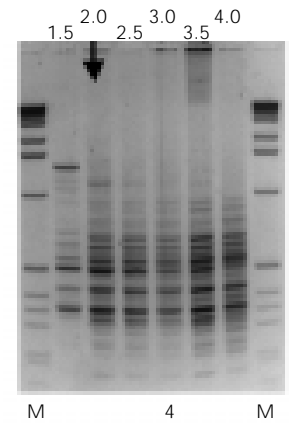

D

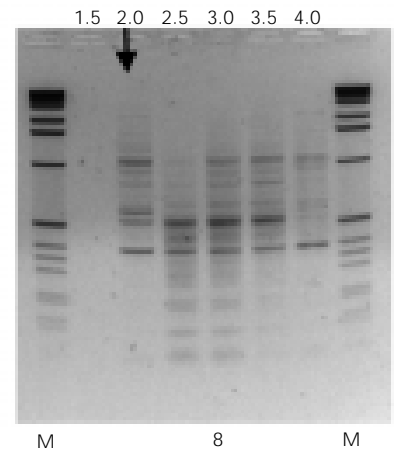

Figure 1. DNA fingerprints obtained for cell lines after DNA amplification with primers INS (A and B) and M13 (C and D). Top of the gels, Concentration of $\mathrm{MgCl}_{2}(\mathrm{mM})$ in the amplification reaction. The arrow points to the concentration of magnesium used as the standard for DNA amplification of these cells. Lane M, 1-kb ladder; lane 1, HeLa; lane 2, HEp-2; lane 3, McCoy; lane 4, NIE-115; lane 5, McCoy; lane 6, C6 36; lane 7, Sf-9; lane 8, VH2. 
Figure 2. Comparison of electrophoretic profiles and curve alignments of DNA fingerprints obtained in independent experiments using AnaGel. A, GH3 cell line amplified with M13; B, NCTC clone 929 cell line amplified with INS.

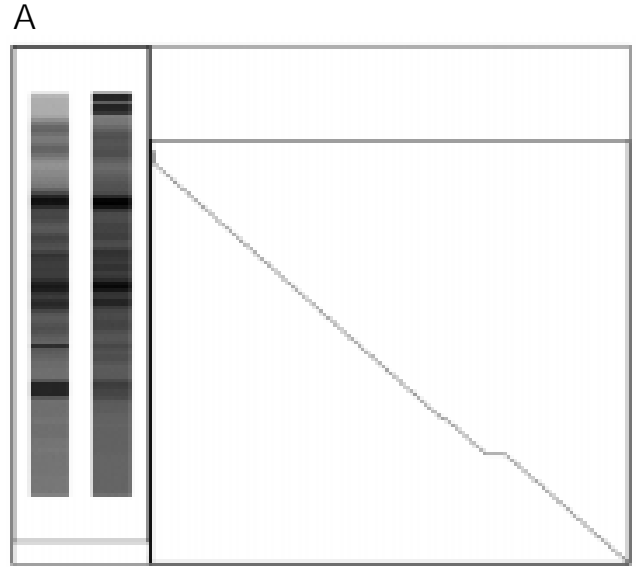

B

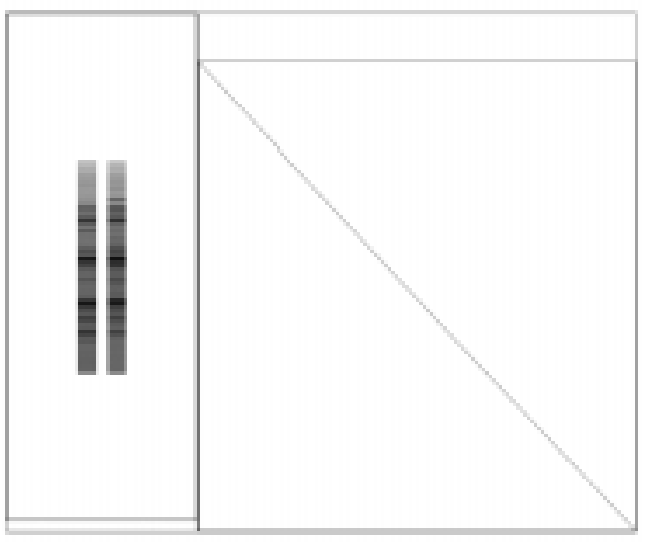

Table 2. Optimal magnesium concentrations (mM) used in the DNA amplification reaction for different cell lines.

\begin{tabular}{lll}
\hline Cell line & \multicolumn{2}{c}{ Primer } \\
\cline { 2 - 3 } & M13 & INS \\
\hline C6 36 & 1.5 & 2.0 \\
GH3 & 1.5 & 1.5 \\
HeLa & 1.5 & 1.5 \\
HEp-2 & 1.5 & 1.5 \\
IMR-32 & 1.5 & 1.5 \\
LM(TK-) & 1.5 & 4.0 \\
MCCoy & 1.5 & 1.5 \\
NCTC clone 929 & 1.5 & 1.5 \\
NIE-115 & 1.5 & 2.0 \\
P3X63Ag8.653 & 1.5 & 1.5 \\
Sf-9 & 1.5 & 4.0 \\
SP2/O.Ag14 & 1.5 & 1.5 \\
Vero & 1.5 & 2.5 \\
VH2 & 2.0 & 3.0 \\
Y1 & 1.5 & 1.5 \\
\end{tabular}

$\mathrm{MgCl}_{2}$, with both primers. The profiles obtained for seven cell lines are shown in Figure 1. Similar electrophoretic profiles were obtained for distinct cell lines, as shown for HeLa and HEp-2 (Figure 1A). When amplification was unsatisfactory or the number of analyzable fragments in the profile was low, a curve of magnesium concentration up to $4.0 \mathrm{mM}$ was constructed in an attempt to improve the fingerprint. These magnesium curves are shown in Figure 1B and 1D for NIE-115 and VH2, with primers INS and M13, respectively. The ideal concentration of $\mathrm{MgCl}_{2}$ in the amplification reaction was established for each cell line and primer and the results are summarized in Table 2.

Figure 2 illustrates the alignment of two fingerprints of the same cell line from independent amplifications after AnaGel processing. A straight line indicates a perfect alignment between two fingerprints. Similar electrophoretic profiles for distinct cell lines were aligned and confirmed to be identical for NCTC clone 929 and Y1, SP2/O.Ag14 and P3X63Ag8.653, HeLa and HEp-2, respectively, with both primers (Figure 3).

\section{Discussion}

DNA fingerprinting is now a well-established method to identify individuals positively and has been found to be also suitable for the authentication of cell lines (for a review, see 13). In the latter case, the main motivation for the preparation of DNA fingerprints is to determine whether lines are the same or not, i.e., line contamination (13).

The procedure used here has been developed to direct PCR amplification to regions rich in VNTR (10). According to the authors who developed DAMD, one should expect differences in the fragments amplified between species but little variation within a species. In our case, 15 cell lines from seven animal species were tested (Table 1). Among the three cell lines of human origin (HeLa, HEp-2 and IMR-32), only two gave similar 
M13

A

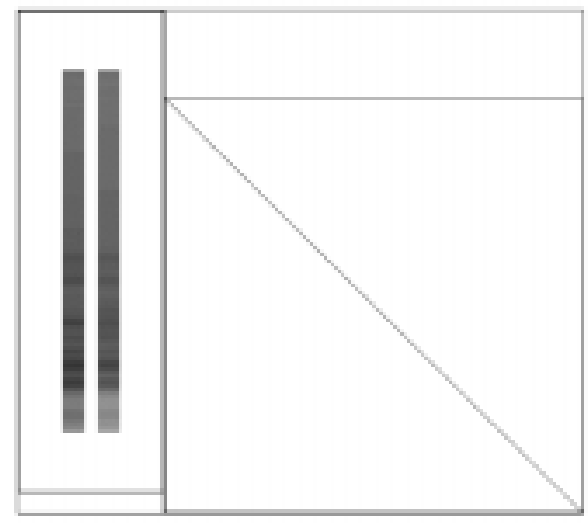

B

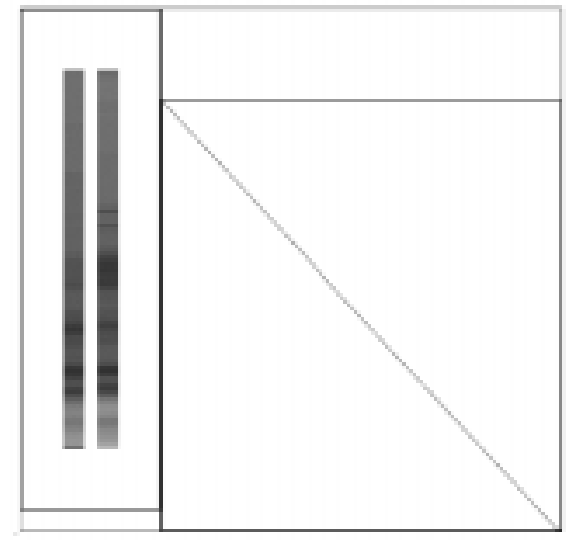

C

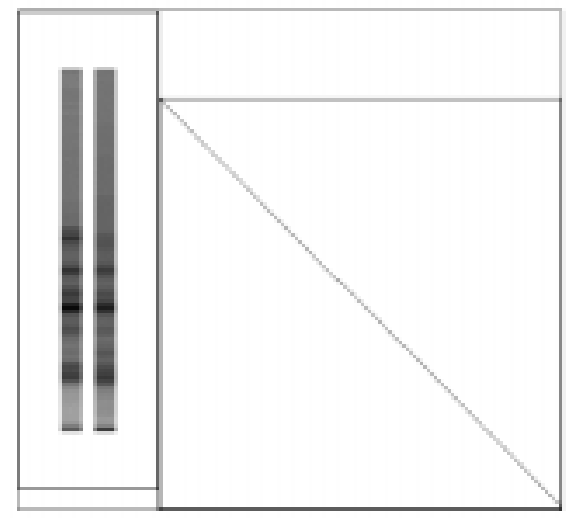

INS
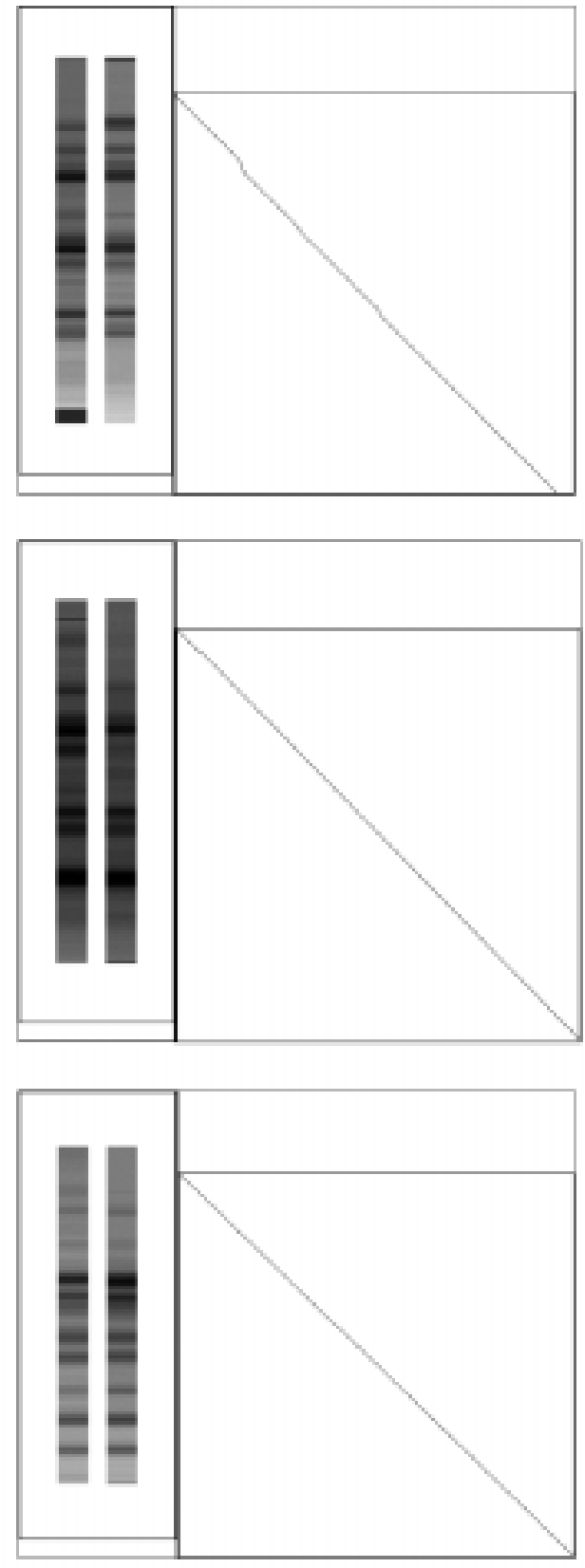

Figure 3. Identical AnaGel profiles generated from DNA fingerprints of distinct cell lines (primers M13 and INS). Cell lines: A, Y1 and NCTC clone 929; B, SP2/ O.Ag14 and P3X63Ag8.653; C, HeLa and HEp-2.

fingerprints (HeLa and HEp-2). This fact is in agreement with a previous study in which virtually identical DNA fingerprints were obtained for these lines using minisatellite probes for hypervariable genetic loci (6). According to the authors, it appears that a number of cell lines, including HEp-2, were contaminated with HeLa early in their his- tory and that the cultures subsequently deposited with the American Type Culture Collection (ATCC) for distribution were simply HeLa lines. Even prolonged culturing under a variety of conditions and the maintenance of these derivative cell lines as separate cultures did not change the DNA fingerprint, demonstrating its stability and heri- 
table character, even after continuous in vitro passages.

Four of seven cell lines from the mice tested gave very similar profiles: P3X63 Ag8.653 and SP2/O.Ag14, Y1 and NCTC clone 929. The fingerprints were compared in pairs with a perfect alignment (Figure 3). Unfortunately, AnaGel does not compare more than two images at a time when they come from different gels. For other cell lines from mice tested here, distinct profiles were obtained and the question remains whether or not the similarity observed in the first case would be due to the fact that they came from the same animal species.

DAMD is a simple and easy method to perform and the fingerprints could be used in the construction of a data base for cell line control. Availability of this base to laboratories involved in cell culturing would allow easy identification of individual lines by comparison to reference profiles as well as comparison of similar lines from different sources and periodic follow-up of cells in culture.

\section{Acknowledgments}

We are grateful to O.S.F. Carvalho and E.Q. Moreira, Department of Computer Science, UFMG, for valuable help with the AnaGel software.

\section{References}

1. Chen TR (1977). In situ demonstration of mycoplasma contamination in cell cultures by fluorescent Hoechst 33258 stain. Experimental Cell Research, 104: 255262.

2. Barile MF (1979). Mycoplasma-tissue cell interactions. In: Tully J G \& Whitcomb RF (Editors), The Mycoplasmas. Vol. II. Academic Press, New York, NY, USA.

3. Wong-Lee J G \& Lovett M (1993). Rapid and sensitive PCR method for identification of Mycoplasma species in tissue culture. In: Persing DH, Smith TF, Tenover FC \& White TJ (Editors), Diagnostic Molecular Microbiology. Principles and Applications. American Society for Microbiology, Washington DC, USA.

4. Gartler SM (1967). Genetic markers as tracers in cell culture. Second Decennial Review Conference on Cell Tissue and Organ Culture. National Cancer Institute
Monograph, 26: 167-195.

5. Gartler SM (1968). Apparent HeLa cell contamination of human heteroploid cell lines. Nature, 217: 750-751.

6. Gilbert DA, Reid YA, Gail MH, Pee D, White C, Hay RJ \& O'Brien SJ (1990). Application of DNA fingerprints for cell line individualization. American J oumal of Human Genetics, 47: 499-514.

7. Welsh J \& McClelland M (1990). Fingerprinting genomes using PCR with arbitrary primers. Nucleic Acids Research, 18: 7213-7218.

8. Williams J G, Kubelik AR, Livak KJ , Rafalski JA \& Tingey SV (1990). DNA polymorphisms amplified by arbitrary primers as useful genetic markers. Nucleic Acids Research, 18: 6531-6535.

9. Riedy MF, Hamilton III WJ \& Aquadro CF (1992). Excess of non-parental bands in offspring from known primate pedigrees assayed using RAPD PCR. Nucleic Acids Research, 25: 918-922.

10. Heath DD, Iwama GK \& Devlin RH (1993). PCR primed with VNTR core sequences yields species specific patterns and hypervariable probes. Nucleic Acids Research, 21: 5782-5785.

11. Morton HJ (1970). A survey of commercially available tissue culture media. In Vitro, 6: 89-108.

12. Pimenta MLA (1996). AnaGel: um sistema de análise de registros eletroforéticos. Master thesis, Department of Computer Science, Federal University of Minas Gerais, Belo Horizonte, MG, Brazil.

13. Webb MBT \& Debenham PG (1992). Cell line characterization by DNA fingerprinting: a review. Developments in Biological Standardization, 76: 39-42. 